Eur. J. Clin. Chem. Clin. Biochem.

Vol. 32, 1994, pp. 675-680

(c) 1994 Walter de Gruyter \& Co. Berlin · New York

\title{
Posttranslational Heterogeneity of Bone Alkaline Phosphatase in Metabolic Bone Disease
}

\author{
By M. R. Langlois ${ }^{1}$, J. R. Delanghe ${ }^{1}$, J. M. Kaufman ${ }^{2}$, M. L. De Buyzere ${ }^{1}$, M. J. Van Hoecke ${ }^{2}$ and \\ G. G. Leroux-Roels \\ 1 Central Laboratory \\ 2 Department of Endocrinology \\ University Hospital, Gent, Belgium
}

(Received February 16/June 8, 1994)

Summary: Bone alkaline phosphatase is a marker of osteoblast activity. In order to study the posttranscriptional modification (glycosylation) of bone alkaline phosphatase in bone disease, we investigated the relationship between mass and catalytic activity of bone alkaline phosphatase in patients with osteoporosis and hyperthyroidism. Serum bone alkaline phosphatase activity was measured after lectin precipitation using the Iso-ALP test kit. Mass concentration of bone alkaline phosphatase was determined with an immunoradiometric assay (Tandem- $R$ Ostase). In general, serum bone alkaline phosphatase mass and activity concentration correlated well. The activity : mass ratio of bone alkaline phosphatase was low in hyperthyroidism. Activation energy of the reaction catalysed by bone alkaline phosphatase was high in osteoporosis and in hyperthyroidism. Experiments with neuraminidase digestion further demonstrated that the thermodynamic heterogeneity of bone alkaline phosphatase can be explained by a different glycosylation of the enzyme.

\section{Introduction}

The metabolic activity of human bone tissue can be studied in serum and urine. In serum, the circulating levels of alkaline phosphatase ${ }^{1}$ ) and its bone isoform, osteocalcin (bone Gla protein, BGP) and type I procollagen are markers of osteoblast activity (bone formation) $(1,2)$. Total serum alkaline phosphatase activity is a less specific marker because it also partly originates from tissues other than bone.

The alkaline phosphatase activity in human serum may originate from the liver, the skeleton, the gastrointestinal tract, the kidney, the placenta and certain tumours (3). Intestinal and placental alkaline phosphatase are true isoenzymes encoded by separate genetic loci, while liver, bone, renal and biliary alkaline phosphatase (macromolecular liver fraction, liver fast alkaline phospha-

\section{1) Enzymes:}

Alkaline phosphatase (Orthophosphoric-monoester phosphohydrolase (alkaline optimum); EC 3.1.3.1) tase) are products of a single gene and differ only as a result of posttranslational modification $(4,5)$. Placental alkaline phosphatase is characterized by multiple alleles (6). The differences between bone and liver alkaline phosphatase isoforms are due to the manner of sialic acid linkage and the attachment of the O-linked sugar moiety (7).

Methods used to separate bone alkaline phosphatase from tike other isoforms include electrophoresis, chemical inhibition and heat denaturation, but all these procedures are technically difficult and have poor resolution (8). The different properties of bone alkaline phosphatase and liver alkaline phosphatase in these methods reflect differences in glycosylation $(9,10)$, as confirmed by partial desialylation experiments with neuraminidase (11). Rosalki \& Ying Foo (12) reported the selective binding of wheat germ lectin (from Tititicum vulgare) to bone alkaline phosphatase and not to liver alkaline phosphatase, which suggests that only bone alkaline 
phosphatase contains $\mathrm{N}$-acetylglucosamine residues in its carbohydrate moiety (13).

Two alternative techniques for quantitating bone alkaline phosphatase based on lectin precipitation and monoclonal antibodies are now available. We used both methods to investigate the relationship between mass and catalytic activity of bone alkaline phosphatase, in order to study the modification of bone alkaline phosphatase. Furthermore, the catalytic quality of bone alkaline phosphatase was evaluated by activation energy determination. Two specific groups of patients with metabolic bone disease were studied: osteoporosis and hyperthyroidism.

\section{Materials and Methods}

\section{Subjects}

Blood was collected, allowed to clot and centrifuged $(1000 \mathrm{~g}, 10$ $\min , 20^{\circ} \mathrm{C}$ ). The supernatant serum was collected for analysis. A group of 14 healthy blood donors (age: $43 \pm 14$ years; 5 males, 9 females) was used as a control group. Thirty four patients with osteoporosis (age: $57 \pm 12$ years; 8 males, 26 females) were studied. The female osteoporosis group consisted of premenopausal $(n=5)$ and post-menopausal $(n=21)$ women. Eight patients (24\%) had a bone fracture due to osteoporosis. All osteoporosis patients underwent an axial bone densitometry. Concomitantly, patients with hyperthyroidism ( $n=78$; age: $52 \pm 13$ years; 28 males, 50 females) were studied. The subjects with clinical suspicion or evidence of liver, biliary or renal disease and patients receiving glucocorticoid therapy were excluded from analysis. None of the female subjects examined was pregnant. Postmenopausal osteoporotic women were not receiving any hormonal replacement therapy at the time of study.

\section{Measurement of total alkaline phosphatase activity}

We determined alkaline phosphatase activity in serum at $37.0^{\circ} \mathrm{C}$ according to the IFCC recommendation (14) (Boehringer, Mannheim, Germany) on a HITACHI 747 analyser (Boehringer, Mannheim, Germany).

\section{Measurement of bone alkaline phosphatase activity by} lectin precipitation

The precipitation procedure was performed with the Iso-ALP test kit (Boehringer, Mannheim, Germany). The assay utilizes wheat germ agglutinin as precipitating agent based on the principle described by Rosalki \& Ying Foo (12) and simplified by Behr \& Barnert (15). The kit contains a solution of wheat germ agglutinin in acetate buffer, $\mathrm{pH} 4.5$, containing $20 \mathrm{ml} / \mathrm{l}$ Triton X-100 to prevent co-precipitation of biliary alkaline phosphatase. We mixed equal amounts $(100 \mu \mathrm{l})$ of lectin solution and serum. After incubation for 30 minutes at room temperature; the mixture was centrifuged at $10000 \mathrm{~g}$ for $2.5 \mathrm{~min}$. Total alkaline phosphatase and residual alkaline phosphatase activity in the supernatant were determined. Bone alkaline phosphatase activity was calculated using the equation

bone alkaline phosphatase $(\mathrm{U} / \mathrm{l})=1.118 \times$ total activity $(\mathrm{U} / \mathrm{l})$ $-2.35 \times$ supernate activity (U/I) (16).

Measurement of bone alkaline phosphatase mass concentration by immunoradiometric assay

Mass concentration of bone alkaline phosphatase was determined making use of a solid phase, two site immunoradiometric assay
(IRMA) (17). The kit (Tandem-R Ostase, purchased from Hybritech Inc., San Diego, CA, USA) utilizes two monoclonal antibodies which are 7 times more reactive with bone alkaline phosphatase than with liver alkaline phosphatase. The assay was run overnight (incubation time: $19 \mathrm{~h}$ ) at $2-8^{\circ} \mathrm{C}$. Measurements were made with an LKB Wallace 1261 gamma-counter (Turku, Finland).

:

Determination of bone alkaline phosphatase activation energy

We eluted bone alkaline phosphatase from the lectin precipitates by adding $100 \mu \mathrm{l}$ of $\mathrm{N}$-acetylglucosamine (Sigma Chemicals Co., St Louis, MO, USA), $45 \mathrm{mmol} / \mathrm{l}$ in saline solution (12). Activation energy of the reaction catalysed by bone alkaline phosphatase was calculated according to the Arrhenius equation

$$
\ln \left(k_{1} / k_{2}\right)=\text { activation energy } / R\left(1 / T_{1}-1 / T_{2}\right),
$$

where $k_{1}$ and $k_{2}$ represent catalytic activities at absolute temperatures, $T_{1}$ and $T_{2}$, and $R$ is the universal gas constant $(8.314 \mathrm{~J} / \mathrm{mol}$ - K) (18). The standard temperature interval for determination of the apparent activation energy was $303.14-310.14 \mathrm{~K}$ (30.0$37.0^{\circ} \mathrm{C}$ ). At both temperatures, bone alkaline phosphatase activity was measured on a HITACHI 747 analyser (Boehringer, Mannheim, Germany) using the IFCC method.

Neuraminidase treatment of bone alkaline phosphatase

Wheat germ agglutinin precipitates from blood donors were resuspended as mentioned above in $\mathrm{N}$-acetylglucosamine solution and used as a bone alkaline phosphatase fraction. Samples were incubated with neuraminidase (20 U/l; EC 3.2.1.18, from Clostridium perfringens), purchased from Sigma Chemicals Co. (St Louis, MO, USA) (15). Ten $\mu$ l of neuraminidase were added to a $100 \mu \mathrm{l}$ sample. After incubation for $1 \mathrm{~h}, 2 \mathrm{~h}$, and $3 \mathrm{~h}$ at $37^{\circ} \mathrm{C}$, activation energy of bone alkaline phosphatase was evaluated and compared with the blank.

Analytical performance of

bone alkaline phosphatase kits

Coefficients of variation were calculated by analysing serum pools (total alkaline phosphatase activity: $75.7 \pm 22.2 \mathrm{U} /$, mean bone alkaline phosphatase activity: $36.8 \pm 16.9 \mathrm{U} / \mathrm{l}$, mean bone alkaline phosphatase mass concentration: $17.5 \pm 7.2 \mu \mathrm{g} / \mathrm{l}$ ). Between-run CVs were obtained using data on 10 consecutive days.

\section{Thyroid quantitative analysis}

In healthy blood donors and in hyperthyroidism patients, thyrotropin (TSH, RIA-gnost, hTSH, Behringwerke AG, Marburg, Germany) and free T4 (Amerlex-MAB* FT4, Kodak Clinical Diagnostics Ltd, Amersham, UK) were assayed using commercial immunoassays.

\section{Statistics}

Data are given as mean \pm S.D. Differences between groups were compared using a two-tailed Mann-Whitney U-test. Correlation analysis was performed with the Pearson correlation test.

\section{Results}

\section{Mass and activity concentration of} bone alkaline phosphatase

Within- and between-run coefficients of variation (CV) for the Iso-ALP kit were 3.5 and $5.9 \%$ respectively. The 
Tab. 1 Total alkaline phosphatase activity, bone alkaline phosphatase activity, bone alkaline phosphatase mass concentration, bone alkaline phosphatase specific activity, and activation energy in the study groups

\begin{tabular}{ccc}
$\begin{array}{l}\text { Blood donors } \\
(\mathrm{n}=14)\end{array}$ & $\begin{array}{l}\text { Osteoporosis } \\
(\mathrm{n}=34)\end{array}$ & $\begin{array}{l}\text { Hyperthyroidism } \\
(\mathrm{n}=78)\end{array}$ \\
\hline $69.0 \pm 21.2$ & $70.9 \pm 55.8$ & $89.9 \pm 46.8$ \\
$34.7 \pm 18.8$ & $30.5 \pm 42.5$ & $35.2 \pm 33.6$ \\
$16.9 \pm 5.5$ & $9.2 \pm 3.6$ & $21.8 \pm 17.2$ \\
$2.23 \pm 1.32$ & $2.41 \pm 2.10$ & $\left.1.59 \pm 0.77^{2}\right)$ \\
$37.7 \pm 5.9$ & $\left.63.3 \pm 11.8^{3}\right)$ & $\left.58.5 \pm 18.8^{4}\right)$
\end{tabular}

3) $\mathrm{p}<0.001$ compared with blood donors

4) $\mathrm{p}<0.05$ compared with blood donors

2) $\mathrm{p}<0.05$ compared with blood donors; $\mathrm{p}<0.001$ compared with osteoporosis

Tandem-R Ostase assay had a within-run CV of $4.1 \%$ and a between-run CV of $7.2 \%$. The bone alkaline phosphatase catalytic activity and mass concentration values obtained in the different groups are shown in table 1. Compared with the healthy blood donors, serum bone alkaline phosphatase concentrations in the osteoporosis and hyperthyroidism groups show a broader range. In general, bone alkaline phosphatase mass and activity concentration correlate well. Figure 1 depicts the correlation between mass and activity concentration of bone alkaline phosphatase: $\log y$ (serum bone alkaline phosphatase activity; $\mathrm{U} / \mathrm{l}$ ) $=1.0 \log \mathrm{x}$ (serum bone alkaline phosphatase mass concentration; $\mu \mathrm{g} / \mathrm{l})+0.180$, $\mathrm{r}=0.800, \mathrm{~S}_{\mathrm{yx}}=34.7$.

\section{Correlation between total alkaline}

phosphatase activity and bone alkaline phosphatase

The total serum alkaline phosphatase activities in the study groups are listed in table 1 . Serum activity of bone alkaline phosphatase generally shows a good correlation with the total serum alkaline phosphatase activity: y (se-

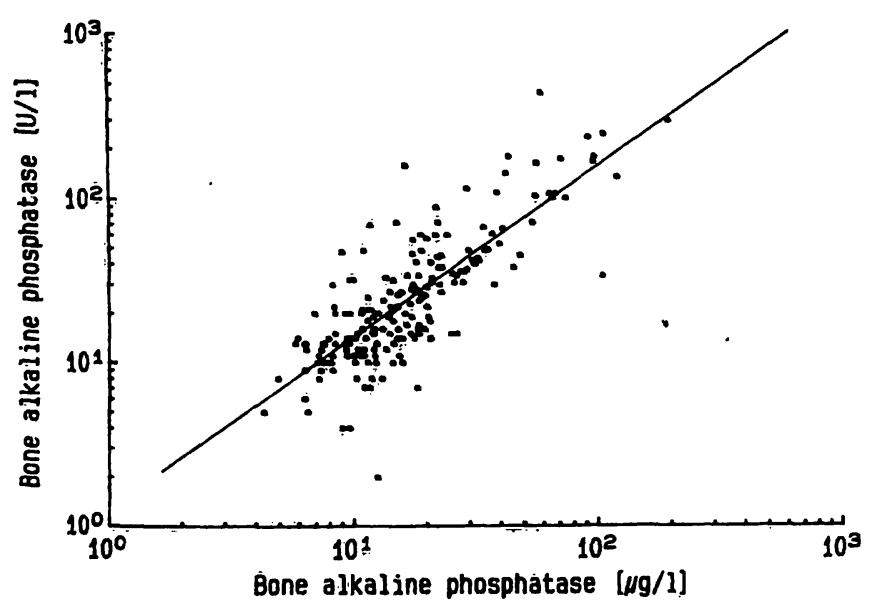

Fig. 1 Correlation between bone alkaline phosphatase mass and activity concentration in the overall population, depicted on a logarithmic scale: $\log y$ (serum activity concentration; $\mathrm{U} / \mathrm{I})=1.0 \cdot \log \mathrm{x}$ (serum bone alkaline phosphatase mass concentration; $\mu \mathrm{g} / \mathrm{l}$ ) $+0.18, \mathrm{r}=0.800, \mathrm{~S}_{\mathrm{yx}}=34.7$. rum bone alkaline phosphatase activity; $U / 1)=0.4 \mathrm{x}$ (serum total alkaline phosphatase activity; $\mathrm{U} / \mathrm{l}$ ) -1.176 , $\mathrm{r}=0.840, \mathrm{~S}_{\mathrm{yx}}=30.8$. Similarly, serum bone alkaline phosphatase mass concentration is correlated with the total alkaline phosphatase activity in serum: y (serum bone alkaline phosphatase mass concentration; $\mu \mathrm{g} / \mathrm{l}$ ) $=0.19 \times$ (serum total alkaline phosphatase activity; $\mathrm{U} / \mathrm{l}$ ) $+3.261, \mathrm{r}=0.889, \mathrm{~S}_{\mathrm{yx}}=11.5$.

\section{Activity versus mass concentration of bone alkaline phosphatase}

In the blood donors, the activity : mass ratio of serum bone alkaline phosphatase at $37^{\circ} \mathrm{C}$ is $2.23 \pm 1.32 \mathrm{U} / \mu \mathrm{g}$ (tab. 1). Between the osteoporosis and hyperthyroidism groups, the bone alkaline phosphatase activity : mass ratio is significantly different: $2.41 \pm 2.10 \mathrm{U} / \mu \mathrm{g}$ vs. 1.59 $\pm 0.77 \mathrm{U} / \mu \mathrm{g}(\mathrm{p}<0.001)$. In hyperthyroidism, the bone alkaline phosphatase activity : mass ratio also differs from that of the controls $(p<0.05)$. For all groups, the bone alkaline phosphatase activity: mass ratio was correlated with its serum activity concentration at $37^{\circ} \mathrm{C}$ : y (bone alkaline phosphatase activity: mass ratio; $\mathrm{U} / \mu \mathrm{g}$ ) $=0.06 \times$ (serum bone alkaline phosphatase activity; $\mathrm{U} / \mathrm{l}$ ) $+0.214, \mathrm{r}=0.832, \mathrm{~S}_{\mathrm{yx}}=0.76$ (blood donors); y (bone alkaline phosphatase activity : mass ratio; $\mathrm{U} / \mu \mathrm{g}$ ) $=0.03 \times$ (serum bone alkaline phosphatase activity; $U / 1)$ $+1.387, \mathrm{r}=0.761, \mathrm{~S}_{\mathrm{yx}}=1.47$ (osteoporosis); and $\mathrm{y}$ (bone alkaline phosphatase activity: mass ratio; $\mathrm{U} / \mu \mathrm{g}$ ) $=0.01 \times$ (serum bone alkaline phosphatase activity; $\mathrm{U} / \mathrm{l}$ ) $+1.05, \mathrm{r}=0.572, \mathrm{~S}_{\mathrm{yx}}=0.71$ (hyperthyroidism).

\section{Activation energy of bone alkaline phosphatase}

The catalytic quality of bone alkaline phosphatase, as evaluated by determination of its activation energy, was different between the study groups. In the healthy blood donors, activation energy of the reaction catalysed by bone alkaline phosphatase was $37.7 \pm 5.9 \mathrm{~kJ} / \mathrm{mol}$. As shown in table 1 , activation energy of bone alkaline 
phosphatase was increased in osteoporosis $(63.3 \pm 11.8$ $\mathrm{kJ} / \mathrm{mol}, \mathrm{p}<0.001)$ and in hyperthyroidism $(58.5 \pm 18.8$ $\mathrm{kJ} / \mathrm{mol}, \mathrm{p}<0.05$ ).

\section{Effects of neuraminidase treatment on activation energy}

Neuraminidase treatment of the bone alkaline phosphatase fractions obtained from 4 healthy blood donors resulted in an increase in activation energy. Prior to treatment, the activation energy of bone alkaline phosphatase was $38.0 \pm 5.1 \mathrm{~kJ} / \mathrm{mol}$. Blank values (untreated samples) remained stable during the experiment. After $1 \mathrm{~h}$ incubation, the activation energy of bone alkaline phosphatase was $57.0 \pm 1.2 \mathrm{~kJ} / \mathrm{mol}(\mathrm{p}<0.01)$. After $2 \mathrm{~h}$ and $3 \mathrm{~h}$, the activation energy rose to $66.1 \pm 8.9 \mathrm{~kJ} / \mathrm{mol}$ and $75.3 \pm 11.0 \mathrm{~kJ} / \mathrm{mol}$ respectively.

\section{Effects of age, sex, and disease}

For all groups, we found no correlations between the subjects' age and total alkaline phosphatase activity, bone alkaline phosphatase activity, bone alkaline phosphatase mass concentration, bone alkaline phosphatase activity: mass ratio, or activation energy. Similarly, there were no sex differences for these quantities.

In the osteoporosis group, patients with postmenopausal osteoporosis showed higher $(p<0.05)$ total alkaline phosphatase activity and bone alkaline phosphatase mass (tab. 2). A history of fractures was not significantly correlated with a change in bone alkaline phosphatase values: $26.6 \pm 25.1 \mathrm{U} / 1$ and $9.3 \pm 1.9 \mu \mathrm{g} / 1$ (subgroup with bone fractures) vs. $25.5 \pm 37.9 \mathrm{U} / 1$ and $9.2 \pm 3.7$ $\mu \mathrm{g} / \mathrm{l}$ for the subgroup without fractures. The axial bone densitometry (expressed as age- and sex-matched $z$ scores) correlated well with the bone alkaline phosphatase values: y (bone alkaline phosphatase activity: $\mathrm{U} / \mathrm{l}$ ) $=12.84 \times$ (z-score $)+42.0 ; \mathrm{r}=0.634, \mathrm{~S}_{\mathrm{yx}}=14.33$ and y (bone alkaline phosphatase mass; $\mu \mathrm{g} / \mathrm{l})=1.66 \mathrm{x}(\mathrm{z}-$ score) $+11.9 ; \mathrm{r}=0.450, \mathrm{~S}_{\mathrm{yx}}=3.02$.

In the reference population, thyrotropin and FT4 values were respectively $1.68 \pm 1.22 \mathrm{mU} / \mathrm{l}$ and $14 \pm 2 \mathrm{ng} / \mathrm{l}$. In the hyperthyroidism group, thyrotropin and FT4 values were $0.02 \pm 0.02 \mathrm{mU} / \mathrm{l}(\mathrm{p}<0.001)$ and $29 \pm 12 \mathrm{ng} / 1$ $(p<0.05)$. According to the FT4 values, the hyperthyroidism group could be subdivided into patients with FT4 less than $18 \mathrm{ng} / 1(\mathrm{n}=38)$, FT4 values between 18 and $30 \mathrm{ng} / 1(\mathrm{n}=33)$, and FT4 values $>30 \mathrm{ng} / \mathrm{l}(\mathrm{n}=7)$. No differences in bone alkaline phosphatase mass or activity were found between these subgroups. No significant correlations could be calculated between FT4 values and total alkaline phosphatase activity, bone alkaline phosphatase activity, bone alkaline phosphatase mass concentration, bone alkaline phosphatase activity : mass ratio, or activation energy.

\section{Discussion}

In this study, we used two new commercially available methods for measuring the mass and activity concentration of bone alkaline phosphatasè. Analyses were performed on a study group of healthy blood donors and patients with osteoporosis and hyperthyroidism, a disease associated with metabolic bone disease (19). In a recent multi-centre evaluation, the Isso-ALP lectin precipitation kit was found to be suitable for quantitation of serum bone alkaline phosphatase in routine analysis (16). We compared this method with a recently developed solid phase immunoassay (Tandem-R Ostase). In general, we noted that serum bone alkaline phosphatase mass and activity concentration correlate well. In our opinion, both IRMA and lectin precipitation methods offer a resolution that is equivalent, if not superior, to any other technique for separating bone alkaline phosphatase from liver alkaline phosphatase. The quality of the separation and technical simplicity mean that both assays provide a useful alternative for measuring bone alkaline phosphatase. However, in each of the used methods, the binding is incomplete and not completely specific.

A broad variation from normal to very high serum bone alkaline phosphatase activities is found in the osteoporosis and hyperthyroidism groups, dependent on the clinical picture and the level of bone turnover. In patients with less dramatic skeletal involvement, any changes in

Tab. 2 Osteoporosis classification and bone alkaline phosphatase

\begin{tabular}{|c|c|c|c|c|}
\hline \multirow[b]{3}{*}{ Total alkaline nhosnhatase activityl) } & \multirow[b]{3}{*}{$\mathrm{U} / 1$} & \multicolumn{2}{|c|}{ Females $(n=26)$} & \multirow{2}{*}{$\begin{array}{l}\text { Males } \\
(n=8)\end{array}$} \\
\hline & & $\begin{array}{l}\text { premenopausal } \\
(\mathrm{n}=5)\end{array}$ & $\begin{array}{l}\text { postmenopausal } \\
(\mathrm{n}=21)\end{array}$ & \\
\hline & & $50.7 \pm 24.9$ & $\left.85.7 \pm 48.3^{2}\right)$ & $44.2 \pm 5.6$ \\
\hline Bone alkaline phosphatase activity ${ }^{1}$ ) & $\mathrm{U} / \mathrm{H}$ & $26.9 \pm 15.8$ & $33.7 \pm 42.6$ & $23.8 \pm 14.2$ \\
\hline Bone alkaline phosphatase mass concentration ${ }^{1}$ ) & $\mu \mathrm{g} / 1$ & $7.8 \pm 1.6$ & $\left.10.6 \pm 3.4^{2}\right)$ & $6.6 \pm 2.5$ \\
\hline Activity to mass ratio ${ }^{1}$ ) & $\mathrm{U} / \mu \mathrm{g}$ 。 & $1.95 \pm 0.21$ & $2.78 \pm 2.69$ & $1.94 \pm 0: 96$ \\
\hline
\end{tabular}

$\begin{array}{ll}\text { 1) } \text { mean } \pm \mathrm{SD} & \text { 2) } \mathrm{p}<0.05 \text { compared with others }\end{array}$ 
bone alkaline phosphatase only make a small contribution to the circulating pool of the enzyme (1). The elevation of bone alkaline phosphatase in serum is related to bone rebuilding and not to bone resorption, and thus the levels may be normal in the early stages of osteoporosis (20). Serum bone alkaline phosphatase increases as the condition deteriorates and resorption and remodelling co-exist. An increase of bone alkaline phosphatase in hyperthyroidism can be explained by a direct action of thyroid hormones on osteoblasts (19).

Using both bone alkaline phosphatase mass and activity concentration, we calculated the activity : mass ratio of the enzyme in the study groups. The activity : mass ratio of serum bone alkaline phosphatase at $37^{\circ} \mathrm{C}$ is decreased in hyperthyroidism. For all study groups, the activity : mass ratio of bone alkaline phosphatase is correlated with its serum activity at $37^{\circ} \mathrm{C}$ and is thus dependent on the degree of bone turnover.

In the temperature interval $30^{\circ} \mathrm{C}-37^{\circ} \mathrm{C}$, the activation energy of the reaction catalysed by bone alkaline phosphatase also differed. In both osteoporosis and hyperthyroidism, the activation energy of bone alkaline phosphatase is increased, indicating a loss of catalytic quality of the enzyme. These results suggest the existence of a thermodynamic heterogeneity of bone alkaline phosphatase in metabolic bone disease.

Our findings are in agreement with those of several authors, who suggested the existence of a posttranslational microheterogeneity of bone alkaline phosphatase (20). Multiple bands of bone alkaline phosphatase have been identified by isoelectric focusing of sera from healthy adults $(21,22)$. After separation of alkaline phosphatase isoforms, using high performance liquid chromatogra-

\section{References}

1. Deftos, L. J. (1991) Bone protein and peptide assays in the diagnosis and management of skeletal disease. Clin. Chem. 37, 1143-1148.

2. Duda, R. J., O’Brièn, J. F., Katzmann, J. A., Peterson, J. M., Mann, K. G. \& Riggs, B. L. (1988) Concurrent assays of circulating bone Gla-protein and bone alkaline phosphatase: Effects of sex, age, and metabolic bone disease. J. Glin. Endocrinol. Metab. 66, 951-957.

3. Moss, D. W. (1982) Alkaline phosphatase isoenżymes [Review]. Clin. Chem. 28, 2007-2016.

4. Moss, D. W. (1986) Multiple forms of acid and alkaline phosphatases: Genetics, expression and tissue-specific modification. Clin. Chim. Acta 161, 123 -135.

5. Moss, D. \& Whitaker, K. (1985) Modification of alkaline phosphatases by treatment with glycosidases. Enzyme 34, 212216.

6. Wahren, B., Hinkula, J., Stigbrand, T., Jeppson, A., Andersson, L., Esposti, P. L., Edsmyr, F. \& Millan, J. L. (1986) Phenotypes of alkaline phosphatase in seminoma sera as defined by monoclonal antibodies. Int. J. Cancer 37, 595-600. phy (HPLC) on anion exchange columns, two bone fractions were found in bone tissue extracts and in serum from a growing child (23). Furthermore, one of the bone fractions was preferentially elevated in osteoporosis, osteomalacia, bone metastases and Paget's disease (24). Similarly, two bands of bone alkaline phosphatase were separated using affinity electrophoresis of human serum in agarose gel containing wheat germ lectin, suggesting differences in the affinity for lectin and/or the number of $\mathrm{N}$-acetylglucosamine and sialic acid residues (25). Differences in glycosylation and molecular mass have been shown between neonatal and adult forms of bone alkaline phosphatase (26). Carbohydrate side chain heterogeneity of bone alkaline phosphatase has also been suggested in patients with Paget's disease and hyperparathyroidism (26). Furthermore, high performance affinity chromatography (HPAC) against wheatgerm lectin demonstrated a change in the glycosylation pattern of bone alkaline phosphatase in bone disease (27).

In conclusion, using two alternative methods for measuring serum bone alkaline phosphatase mass and activity concentration, we were able to demonstrate a heterogeneity of bone alkaline phosphatase in metabolic bone disease.

Our findings suggest that a different posttranslational modification of bone alkaline phosphatase occurs in pathological conditions.

\section{Acknowledgement}

We wish to thank Boehringer Mannheim and Hybritech Europe S. A. for kindly providing the necessary reagents for this study. Ms. Mira Vanderbeke is thanked for her skilful assistance.
7. Miura, M., Sakagishi, Y., Hata, K. \& Komoda, T. (1994) Differences between the sugar moieties of liver- and bone-type alkaline phosphatases: A re-evaluation. Ann. Clin. Biochem. $31,25-30$.

8. Chapman, J. F., Woodard, L. L. \& Silverman, L. M. (1989) Alkaline phosphatase isoenzymes. In: Clinical Chemistry: Theory, Analysis, and Correlation, 2nd ed. (Kaplan, L. A. \& Pesce, A. J., eds.) pp. 902-906, CV Mosby, St. Louis.

9. Harris, H. (1989) The human alkaline phosphatases: What we know and what we don't know [Review]. Clin. Chim. Acta $186,113-150$.

10. Moss, D. W. (1992) Perspectives in alkaline phosphatase research. Clin. Chem. 38, 2486-2492.

11. Moss, D. E. \& Edwards, R. K. (1984) Improved electrophoretic resolution of bone and liver alkaline phosphatases resulting from partial digestion with neuraminidase. Clin. Chim. Acta $143,177-182$.

12. Rosalki, S. B. \& Ying Foo, A. (1984) Two new methods for separating and quantifying bone and liver alkaline phosphatase isoenzymes in plasma. Clin. Chem. 30, 1182-1186. 
13. Schreiber, W. E. \& Whitta, L. (1986) Alkaline phosphatase isoenzymes resolved by electrophoresis on lectin-containing agarose gel. Clin. Chem. 32, 1570-1573.

14. International Federation of Clinical Chemistry; Scientific Committee, Expert Panel on Enzymes (1983) IFCC methods for measurement of enzymes. Part V: IFCC method for alkaline phosphatase. IFCC document stage 1, draft 3, 1981. J. Clin. Chem. Clin. Biochem. 21, 731-748.

15. Behr, W. \& Barnert, J. (1986) Quantification of bone alkaline phosphatase in serum by precipitation with wheat-germ lectin: A simplified method and its clinical plausibility. Clin. Chem. 32, 1960-1966.

16. Rosalki, S. B., Ying Foo, A., Burlina, A., Prellwitz, W., Stieber, P., Neumeier, D., Klein, G., Poppe, W. A. \& Bodenmuller, H. (1993) Multicenter evaluation of Iso-ALP test kit for measurement of bone alkaline phosphatase activity in serum and plasma. Clin. Chem. 39, 648-652.

17. Panigrahi, K., Delmas, P., Singer, F., Ryan, W., Reiss, O., Fisher, R., Miller, P., Mizrahi, I., Darte, C., Kress, B. \& Christenson, R. (1994) Characteristics of a two-site immunoradiometric assay for human skeletal alkaline phosphatase in serum. Clin. Chem. 40, 822-828.

18. Langlois, M., Delanghe, J., De Buyzere, M. \& Leroux-Roels, G. (1992) Glycation of human tissue and serum creatine kinase. Clin. Chim. Acta 211, 83-92.

19. Tibi, L., Patrick, A. W., Leslie, P., Toft, A. D. \& Smith, A. F. (1989) Alkaline phosphatase isoenzymes in plasma in hyperthyroidism. Clin. Chem. 35, 1427-1430.

20. Price, C. P. (1993) Multiple forms of human serum alkaline phosphatase: Detection and quantitation. Ann. Clin. Biochem. 30, 355-372.

21. Sinha, P. K., Bianchi-Bosisio, A., Meyer-Sabellek, W. \& Righetti, P. G. (1986) Resolution of alkaline phosphatase isoen- zymes in serum by isoelectric focusing in immobilized $\mathrm{pH}$ gradients. Clin. Chem. 32, 1264-1268.

22. Griffiths, J. \& Black, J. (1987) Separation and identification of alkaline phosphatase isoenzymes and isoforms in serum of healthy persons by isoelectric focusing. Clin. Chem. 33, 2171-2177.

23. Schoenau, E., Herzog, K. H. \& Boehles, H. J. (1986) Liquidchromatographic determination of isoenzymes of alkáline phosphatase in serum and tissue homogenates. Clin. Chem. 32, 816-818.

24. Parviainen, M. T., Galloway, J. H., Towers, J. H. \& Kanis, J. A. (1988) Alkaline phosphatase isoenzymes in serum detected by high-performance anion-exchange liquid chromatography with detection by enzyme reaction. Clin. Chem. 34, 24062409.

25. Onica, D., Sundblad, L. \& Waldenlind, L. (1986) Affinity electrophoresis of human alkaline phosphatase isoenzymes in agarose gel containing lectin. Clin. Chim. Acta 155, 285-293.

26. Miura, M., Matsuzaki, H., Bailyes, E. M., Koyama, I., Sakagishi, Y., Sekine, T. \& Komoda, T. (1989) Differences between human liver- and bone-type alkaline phosphatases. Clin. Chim. Acta $180,177-188$.

27. Anderson, D. J., Branum, E. L. \& O’Brien, J. F. (1990) Liverand bone-derived isoenzymes of alkaline phosphatase in serum as determined by high-performance affinity chromatography. Clin. Chem. 36, 240-246.

Prof. Dr. Joris Delanghe

Central Laboratory

University Hospital Gent

De Pintelaan 185

B-9000 Gent

Belgium 